\section{Antipsychotic polypharmacy: lessons from antiepileptic polypharmacy}

The concerns discussed in The Psychiatrist ${ }^{1}$ about the causes, complications, management and avoidance of antipsychotic polypharmacy reflect an earlier literature on anti-epileptic polypharmacy. ${ }^{2-4}$

Anti-epileptic polypharmacy is much older than antipsychotic polypharmacy and can be traced at least to the introduction of bromides in the middle of the 19th century. By 1970, patients at epilepsy centres in the UK and Europe were taking a mean of 3.2 drugs per person, of which $84 \%$ were anti-epileptics. In the 1960s and 1970s the availability of blood level monitoring of phenobarbitone, phenytoin, carbamazepine and valproate revealed that most of this polypharmacy was unnecessary, unhelpful and in many patients harmful. As well as previously unsuspected subtle toxic effects on cognition, mood and behaviour, polypharmacy also increased seizure frequency in some patients. In newly diagnosed patients, longterm seizure control was achieved in $70-80 \%$ with carefully monitored monotherapy. The addition of a second drug to those patients uncontrolled by optimum monotherapy resulted in modest improvement in seizure control in only a third, but led to unacceptable toxicity or increased seizures in a quarter. Monotherapy became the gold standard, licensing authorities demanded clinical trials of monotherapy and the incidence of polypharmacy fell rapidly.

Between 1989 and 2004, ten new anti-epileptic drugs were licensed in the UK, only one of which, lamotrigine, has widely available blood level monitoring. The lessons of the 1970s and 1980s have been largely overlooked and polypharmacy has increased again. Even now there has been only one controlled trial in patients with epilepsy unresponsive to optimum monotherapy comparing the policy of adding a second drug with the policy of switching to alternative monotherapy. The probability of remaining seizure-free over the next year was $16 \%$ for patients given a second drug and $14 \%$ for those switched to alternative monotherapy. ${ }^{5}$

For both psychosis and epilepsy, factors which perpetuate polypharmacy are: a lack of understanding of the therapeutic limits of monotherapy or polypharmacy with either class of drug; unawareness of subtle and sometimes serious chronic toxicity; the need to do something in a distressing and chronic situation; misguided claims about the 'rationality' of polypharmacy, based on theoretical views of different mechanisms of drug action or even unproven concepts of synergy.

The problems of monitoring medication and measuring clinical outcome in psychosis are different from epilepsy, but many of the causes of unnecessary and potentially harmful polypharmacy as well as the principles of avoiding such polypharmacy, are likely to be similar.
1 Rajpal R, Owens E, McCauley M. Polypharmacy: should we or shouldn't we? (letter) Psychiatrist 2011; 35: 31-2.

2 Shorvon SD, Reynolds EH. Unnecessary polypharmacy for epilepsy. BM 1977; 1: 1636-7.

3 Reynolds EH, Shorvon SD. Monotherapy or polytherapy for epilepsy? Epilepsia 1981; 22: 1-10.

4 Reynolds EH. Treating refractory epilepsy in adults. BMJ 2006; 332: 561-2.

5 Beghi E, Gatti G, Tonini C, Ben-Menachem E, Chadwick DW, Nikanorova $M$, et al. Adjunctive therapy versus alternative monotherapy in patients with partial epilepsy failing on a single drug: a multicentre, randomised, pragmatic controlled trial. Epilepsy Res 2003; 57: 1-13.

Edward H. Reynolds, honorary senior lecturer, Clinical Neurosciences, King's College London; former consultant neurologist to the Maudsley and King's College Hospitals, London, email: reynolds@buckles.u-net.com

doi: $10.1192 / p b .35 .5 .198$

\section{The rise in the number of Section 2 detentions}

I work on a psychiatric intensive care unit (PICU) and have noticed a significant rise of patients being detained under Section 2 of the Mental Health Act. I recently had the dubious pleasure of being asked to do five hearings for tribunal and hospital managers in 5 working days. In our trust, figures suggest a steady increase for this type of work in recent years, although this may be partially offset by a reduction of such admissions to the acute wards.

Many health and social care professionals seem to be using Section 2 much more frequently than before. Out-ofhours assessments are carried out by duty staff with little or no prior knowledge of the patients and it is inevitable in such circumstances that Section 2 is more often used. This seems appropriate.

However, there is also an uncritical approach to using guidance $^{1}$ that results in Section 2 being used much more frequently now. Whereas Jones makes an argument as to why Section 2 can be preferred to Section 3, the Mental Health Act itself has retained the use of Section 3 as a first option rather than recommend Section 2 be used indiscriminately.

I have yet to see reports of these trends in the literature but this situation is likely to impinge greatly on the workload of consultants and clinicians dealing with PICUs and admission/ treatment wards as well as for administrative staff. The waste of time and resources in dealing with the inevitable extra tribunals must be a good enough reason for the law and code of practice to be made clearer.

1 Jones R. Mental Health Act Manual, 13th Edition. Sweet and Maxwell, 2010.

L. S. Choong, Consultant Psychiatrist, Hadley Unit, Newtown Hospital, Worcester WR5 1JG, email: steve.choong@worcsmhp.nhs.uk

doi: $10.1192 / p b .35 .5 .198 a$ 